\title{
Institutional Delivery Services Utilization and Associated Factors among Mothers who gave Birth in the Last One Year in Jimma Town, Southwest Ethiopia
}

\author{
Yibeltal Siraneh ${ }^{1 *}$ and Fisseha Wondimnew ${ }^{2}$ \\ ${ }^{1}$ Department of Health Economics, Jimma University, Ethiopia \\ ${ }^{2}$ South Nations, Nationality and people regional state health bureau, Ethiopia
}

Submission: September 04, 2018; Published: October 25, 2018

*Corresponding author: Yibeltal Siraneh Belete, Department of Health Economics, Management and Policy, Faculty of Public Health, Institute of Health, Jimma University, Ethiopia, Tel: +251917017092; Email: yibeltal_siraneh@yahoo.com; yibeltalsiraneh@gmail.com

\begin{abstract}
Background: High maternal mortality was a continued challenge for the achievement of Sustainable Development Goal in Sub-Saharan African countries including Ethiopia. Although institutional delivery service utilization ensures safe birth and a key to reduce maternal mortality, interventions at the community and/or institutions were unsatisfactorily reduced maternal mortality. Institutional delivery service utilization is affected by the interaction of personal, socio-cultural, behavioral and institutional factors. Therefore, this study was designed to assess factors associated with institutional delivery service usage and utilization status among mothers who gave birth in the last 12 months in Jimma Town, Oromia Region.
\end{abstract}

Objective: To assess utilization of institutional delivery services and associated factors among mothers who gave birth in the last one year in Jimma town, south-west Ethiopia.

Method: A community based cross sectional study design was used from June 15- July 15in Jimma town south-west of Addis Ababa, Ethiopia. Five Keble were selected randomly by lottery method. Four hundred two mothers who gave birth in the last 12 months were included in the study using systematic random sampling. Data were collected by trained staff health extension workers via face to face interview and pretested structured questionnaire was used to collect data on different variables. The result was interpreted using tables, graphs, chart and figures of percentage. Chi square test was used to analysis association between variables and p-value of i.e. $<0.05$ was presumed to indicate significance of association.

Result: In this study, $74.4 \%$ of women gave birth to their current child at health institution. The chi square association showed that, educational status of the mother $\left(\chi^{2}=71.5442, \mathrm{P}<0.00001\right)$ and their husband $\left(\chi^{2}=95.1494 \mathrm{P}<0.00001\right)$, age at first marriage $\left(\chi^{2}=27.1211, \mathrm{P}<0.00001\right)$, age at first pregnancy $\left(\chi^{2}=41.7694\right.$, gravidity, $\left.\mathrm{P}<0.00001\right)$, occupational status $\left(\chi^{2}=41.6777, \mathrm{P}<0.00001\right)$ parity $\left(\chi^{2}=36.9567, \mathrm{P}<0.00001\right)$, types of pregnancy (planned/unplanned) $\left(\chi^{2}=22.5488, P<0.00001\right)$, and ANC visit during the last pregnancy $\left(\chi^{2}=4.2478, P=0.039301\right)$ frequency of ANC visit $\left(\chi^{2}=2.0773, P=0.149509\right)$ were factors associated with institutional delivery service utilization.

Conclusion: In this study, institutional delivery service utilization is optimal; mothers in Jimma town were more likely to practice institutional delivery. Factors such as age at first marriage, age at first pregnancy, types of pregnancy (planned/unplanned), parity, gravidity, occupation, ANC visit during the last pregnancy, frequency of ANC visit, educational status of the mother and their husband and knowledge of the mothers on pregnancy and delivery services were significantly associated with skilled delivery service utilization

Keywords: Institutional delivery service utilization; Community based cross sectional study; Mothers gave birth in the last 12 months; Jimma town

Abbreviations: AIDS: Acquired Immune Deficiency Syndrome; ANC: Antenatal Care; DHS: Demographic and Health; HD: Home Delivery; HIV: Human Immunodeficiency Virus; ID: Institutional Delivery; MCH: Maternal Child Health; MMR: Maternal Mortality Rate; MOH: Ministry of Health; OR: Odd Ratio; PNC: Postnatal Care; SGA: Small for Gestational Age; TBA: Traditional Birth Attendant; TTBA: Trained Traditional Birth Attendant; WHO: The World Health Organization

\section{Background Information}

Maternal mortality remains high in the developing world. Giving birth in a health facility is associated with lower maternal mortality than giving birth at home. An important component of

efforts to reduce health risks to mothers and children is increasing the proportion of babies that are delivered in health facilities. Giving birth in a medical institution under the care and supervision 
of trained health-care providers promotes child survival and reduces the risk of maternal mortality. Many women lose their lives in the process of giving life. Utilization of health services is affected by a multitude of factors including not only availability, distance, cost, and quality of services, but also by socioeconomic factors and personal health beliefs. In an attempt to understand the factors that determine women's utilization of health services, the role of need, permission, ability, and availability \& reasoned that when permission and ability interact with need, a demand for health services is generated [1].

Obstetric care from a trained provider during delivery is recognized as critical for the reduction of maternal and neonatal mortality. Births delivered at home are usually more likely to be delivered without assistance from a health professional, whereas births delivered at a health facility are more likely to be delivered by a trained health professional. Delivery assisted by skilled providers is the most important proven intervention in reducing maternal mortality and one of the MDG indicators to track national effort towards safe mother hood. In spite of this, 16 percent of births were assisted by a skilled provider: 5 percent by a doctor and 11 percent by a nurse or midwife. About 2 percent of births were assisted by a HEW, and 51 percent of births were assisted by a relative, or some other person. Twenty-seven percent of births were assisted by a traditional birth attendant, while 5 percent of births were unattended. Skilled assistance at delivery increased from 6 to 16 percent in the last fifteen years. The majority of births are attended by a relative or some other person ( 51 percent). Five percent of all births are delivered without any type of assistance at all [2].

Not surprisingly, skilled providers attended an overwhelming majority of births delivered in a health facility compared with births delivered elsewhere. Urban births were more than six times as likely to be attended by skilled providers as rural births. Regional differences in delivery assistance are large. The proportion of births assisted by a skilled provider ranged from 10 percent in Afar to 86 percent in Addis Ababa. Skilled attendance at delivery increases with mother's education and household wealth. As expected, mother's education has a positive relationship with delivery care. Births to women with primary education are almost four times ( 9 percent) more likely and births to women with secondary or higher education are 25 times (58 percent) more likely to receive delivery assistance from a health professional than births to women with no education (2\%). Similarly, assistance by a trained health professional varies by economic status of women [3], Hence, assessing institutional delivery service utilization and associated factors is very important to inform service providers and service users.

\section{Objectives}

\section{General objective}

a) To assess utilization of Institutional delivery services and associated factors among mothers who gave birth in the last one year prior to the study from June 15- July 15inJimma town, Oromia region, Southwest Ethiopia.

\section{Specific objectives}

a) To assess utilization status of institutional delivery services

b) To identify factors associated with utilization of institutional delivery services

\section{Method and Participants}

\section{Study area and period}

Community based cross sectional study was conducted in Jimma town from June 15-July 15, 2016 on women who gave birth 12 months before the study period. Jimma town is located $350 \mathrm{~km}$ south west of Addis Ababa which is the capital city of Ethiopia. Administratively, the town is structured into 17 Keble (4 rural \& 13 urban). According to 2015 census the projected population of the town by 2015 / 16 was estimated to be 182,818 with 91,848 male and 90,970 which is approximately about 1 to 1 male to female ratio where total number of women who gave birth in the last one year was 7170 .

The study design: A community-based cross-sectional study design was used.

Source population: Source populations of the study were all mothers who gave birth in Jimma town in the last 12month.

Study population: All mothers who gave birth in the last 12 months were sampled and included in the study.

\section{Eligibility criteria:}

Inclusion criteria: Women who gave birth in the last 12 months regardless of the outcome and who lived in the study area for at least six months.

Exclusion Criteria: Mothers who are severely ill and unable to hear will be excluded in the interview.

\section{Sample size and sampling technique sample size deter- mination}

The sample size is determined by using a single population proportion formula considering the following assumptions:

Magnitude of institutional delivery service utilization was considered $50 \%$. Therefore, $(\mathrm{p}=0.5)$. Level of significance to be $5 \%(\alpha=0.05), \mathrm{Z} \alpha / 2=1.96$ and,

Margin of error to be $5 \%(d=0.05)$.

The formula for calculating the sample size was,

$$
n=\frac{(Z \alpha / 2)^{2} * P(1-P)}{d^{2}}=\frac{1.96^{2} * 0.5 * 0.5}{(0.05)^{2}}
$$

Where: $\mathrm{n}=$ Initial sample size, $\mathrm{p}=50 \%$

$d^{2}=$ marginal error $=(5 \%), 0.05$

$\mathrm{Z} \alpha / 2=$ standard score at $95 \%$ confidence interval (= 1.96).

$\mathrm{N}=$ total number of mothers who gave birth in the last 12 months 
Since the study population is less than 10,000 , the final sample size (NF) can be calculated by using population correction formula.

$$
\begin{aligned}
& N F=n / 1+n / N=384 / 1+384 / 7170 \\
& N F=364.6=365
\end{aligned}
$$

Non-response rate of $10 \%$ the total calculated sample size was 402 women.

\section{Sampling technique}

Mothers who gave birth in the last 12 months in the Town, regardless of their birth outcome, were included in the sample. Five urban Keble were selected using simple random method (lottery method). Households from each Keble were selected again by systematic random sampling with a sampling interval of 7 . The allocated sample size was obtained using proportional allocation to the size of households found in each Keble. The sampling was started by selecting an element from the list at random and then every $7^{\text {th }}$ household where,7, the sampling interval for interviewing. For those closed houses or the mothers were not present at the time of data collection, after maximum of 3 repeated visits were made I was taking as non- respondent. If there were more than one mother within the same household lottery method was used to select the one to be included in the sample.

\section{Measurement and variables}

Dependent variables: institutional Delivery service utilization

Independent-variables: age, marital status, religious, ethnicity, educational status, economic status (income), occupation, age at first birth, age at first marriage, age at first pregnancy, preference of husband to place of delivery, preference of other family members to place of delivery, past birth outcomes, ANC follows up, decision to seek care, gaining adequate health care.

\section{Data collection tools and procedures}

Data were collected using structured, pre-tested interviewer administered questionnaire. A structured questionnaire developed in English in such a way that it includes all the relevant variables to meet the objective of the study after a review of literature. Socio-demographic, obstetric and maternal data were collected. Home delivery was considered when a mother reported birth at home (other than health institution) to her recent delivery. Data were collected through face to face interview. Data collectors and supervisors were trained for three days on the objectives of the study.

\section{Data processing and analysis}

Data were analyzed and tallied manually by using pen, pencil, paper, calculator and computer. Associations between dependent and independent variables were assessed using chi square at pvalue less than 0.05 was considered as statistically significant.

\section{Quality assurance}

Three staff health extension workers had conducted the face to face interviews and the main investigate \& one nurse had supervised the data collection process. Training was given to the data collectors and supervisors for three days before the actual data collection regarding the aim of study, and data collection tool and procedures going through the questionnaires question by question. In addition, the training also focused on the art of interviewing and clarifying questions that were unclear to the respondents. To ensure data quality, proper designing, translation to the local language (during data collection) and pre-testing of the research tool were done. The filled data was checked for completeness on daily basis and feedback was given to data collectors on the next morning.

\section{Ethical consideration}

Letter of ethical approval was received from Institutional Review Board (IRB) of Jimma University and that was communicated to the town Health Office and Keble. Permission and verbal consent were obtained from each respondent during interview and confidentiality was assured before conducting data collection. All information that was obtained from the individuals was kept confidential. The respondent right was guaranteeing to stop or refuse participation at any time.

\section{Operational Definition \& Definition of Terms}

Preference of place of delivery: The choice of mothers where to give birth (home vs. institutional).

Utilization: Means the extent to which a given group of people uses particular service in a specified period of time.

Maternal death: Is the death of a woman while pregnant or within 42 days of termination of pregnancy, irrespective of the duration and site of the pregnancy, from any cause related to or aggravated by the pregnancy or its management but not from accidental or incidental causes.

Skilled attendants: Refer to people with midwifery skills (midwives, doctors and nurses with additional midwifery education) who have been trained to proficiency in the skills necessary to manage normal deliveries and diagnose, manage or refer obstetric complications' (WHO).

Gravidity: Total number of pregnancies.

Grand multi-parity: A mother who has 5 or more viable previous pregnancies.

Elderly primi-gravida: Any women who experiences her first pregnancy after the age of

35 years.

Teenage pregnancy: is pregnancy in human females under the age of 20 .

Decision to seek care: Mothers tendency towards getting health care service.

Gaining adequate health care: is the maintenance or improvement of health via the diagnosis, treatment, and prevention of disease, illness, injury, and other physical and mental impairments in all women. 
Results

\section{Socio-demographic characteristics}

In this study, a total of 402 mothers who gave birth 12 months prior to study were proposed to be included. Of the total proposed women, 375 mothers were included in the analysis which made the response rate $93.3 \%$ among which $126(31.35 \%)$ were in the age group of 25-29yrs followed by $95(28.6 \%)$ in the age group of 20-24. Majority, $(91.47 \%)$, were currently married with $10\left(2.6 \%{ }^{\wedge}\right)$ were never married. $45.06 \%$ were oromia in their ethnicity and majority $34.13 \%$ were orthodox Christians and a higher proportion $266(71.2 \%)$ of the respondents attended primary education and above followed by $16.27 \%$ were able to read and write while $48(12.8 \%)$ were unable to read and write. Regarding occupational status most of the respondents 140 (36.5\%) were engaged in private business and 93(25.6\%) were merchant followed by $87(24.2 \%)$ were governmental employee. The rest $13.6 \%$ of the respondents were house wife, daily laborer and other field of work. Most of husband's occupation was governmental employ and private. Around 79\% of the respondents had family size of below 4. Regarding to their economic status majority of the respondents $270(72 \%)$ were having $>500$-birr monthly income even though around $7 \%$ of the respondents were having less than 250-birr monthly income. (See Table 1 below).

Table 1: Distribution of Socio-demographic Characteristics of mothers who gave birth in the last 1 year in Jimma town, Ethiopia, 2016.

\begin{tabular}{|c|c|c|c|c|}
\hline S.No & \multicolumn{2}{|c|}{ Socio- economic and Demographic Characteristics } & Frequency & $\%$ \\
\hline \multirow{8}{*}{1} & \multirow{8}{*}{ Age } & $15-19$ & 22 & 2.99 \\
\hline & & $20-24$ & 95 & 28.6 \\
\hline & & $25-29$ & 126 & 31.35 \\
\hline & & $30-34$ & 58 & 16.9 \\
\hline & & $35-39$ & 41 & 11.95 \\
\hline & & $40-44$ & 23 & 5.72 \\
\hline & & $45-49$ & 10 & 2.5 \\
\hline & & Total & 375 & 100 \\
\hline \multirow{7}{*}{2} & \multirow{7}{*}{ Occupation of the mother } & private & 140 & 36.5 \\
\hline & & Governmental employee & 87 & 24.2 \\
\hline & & Merchant & 93 & 25.62 \\
\hline & & Daily laborers & 25 & 6.22 \\
\hline & & House wife & 22 & 5.87 \\
\hline & & Other & 8 & 2.13 \\
\hline & & Total & 375 & 100 \\
\hline \multirow{7}{*}{3} & \multirow{7}{*}{ Occupation of the husband } & private & 96 & 25.6 \\
\hline & & Governmental employee & 124 & 33.07 \\
\hline & & Merchant & 63 & 16.8 \\
\hline & & Daily laborers & 18 & 4.8 \\
\hline & & Farmer & 62 & 16.53 \\
\hline & & Other & 12 & 3.2 \\
\hline & & Total & 375 & 100 \\
\hline \multirow{7}{*}{4} & \multirow{7}{*}{ Educational Status of mothers } & Illiterate & 48 & 12.8 \\
\hline & & Read and write & 61 & 16.27 \\
\hline & & primary Education & 141 & 37.6 \\
\hline & & Secondary school and & \multirow{2}{*}{95} & \multirow{2}{*}{25.33} \\
\hline & & preparatory & & \\
\hline & & College and university & 30 & 8 \\
\hline & & Total & 375 & 100 \\
\hline
\end{tabular}


Journal of Complementary Medicine \& Alternative Healthcare

\begin{tabular}{|c|c|c|c|c|}
\hline \multirow{7}{*}{5} & \multirow{7}{*}{ Educational Status of the husband } & Illiterate & 80 & 22 \\
\hline & & Read and write & 57 & 15.6 \\
\hline & & primary Education & 67 & 18.3 \\
\hline & & Secondary school and & \multirow{2}{*}{107} & \multirow{2}{*}{28.53} \\
\hline & & preparatory & & \\
\hline & & College and university & 54 & 14.4 \\
\hline & & Total & 365 & 100 \\
\hline \multirow{6}{*}{6} & \multirow{6}{*}{ Economic Status } & $100-250$ & 26 & 6.93 \\
\hline & & $251-500$ & 79 & 21.07 \\
\hline & & $501-750$ & 85 & 22.67 \\
\hline & & $751-1000$ & 102 & 27.2 \\
\hline & & $>1000$ birr & 83 & 22.13 \\
\hline & & Total & 375 & 100 \\
\hline \multirow{5}{*}{7} & \multirow{5}{*}{ Ethnicity } & Oromo & 169 & 45.06 \\
\hline & & Gurage & 71 & 18.93 \\
\hline & & Amhara & 117 & 31.2 \\
\hline & & Other & 18 & 4.8 \\
\hline & & Total & 375 & 100 \\
\hline \multirow{5}{*}{8} & \multirow{5}{*}{ Marital Status } & Single & 10 & 2.67 \\
\hline & & Married & 343 & 91.47 \\
\hline & & Divorced & 16 & 4.26 \\
\hline & & Widowed & 6 & 1.6 \\
\hline & & Total & 375 & 100 \\
\hline \multirow{6}{*}{9} & \multirow{6}{*}{ Family Size } & 1 & 58 & 15.47 \\
\hline & & 2 & 157 & 41.87 \\
\hline & & 3 & 81 & 21.6 \\
\hline & & 4 & 62 & 16.53 \\
\hline & & $5+$ & 17 & 4.53 \\
\hline & & Total & 375 & 100 \\
\hline \multirow{6}{*}{10} & \multirow{6}{*}{ Religion } & Muslim & 109 & 29.07 \\
\hline & & Orthodox & 128 & 34.13 \\
\hline & & Protestant & 98 & 26.13 \\
\hline & & Catholic & 22 & 5.87 \\
\hline & & Others & 18 & 4.8 \\
\hline & & Total & 375 & 100 \\
\hline
\end{tabular}

Institutional delivery services utilization, maternal and obstetric variables

One hundred seventy-three $(46.13 \%)$ of mothers had got marriage at their early age $<20$ years while one hundred six $(28.27 \%)$ of the mothers reported as they were less than 20 years old during their first pregnancy. Two hundred twentyseven $(60.53 \%)$ of the mothers were para three and below while two hundred fifteen $(57.33 \%)$ mothers were gravid three and below and one hundred forty-eight mothers was gave birth more than three. Three hundred forty-five (82\%) of the respondents had ever visited health facilities during pregnancy and 304
(81.07\%) of them visited health facilities for ANC purposes during their last pregnancy. Among the mothers who attended ANC, majority, 190(63\%), made more than 2 ANC visits during their last pregnancy. One hundred sixty-five (54.28\%) of mothers attended at hospitals and one hundred twelve (36.8\%) were at health center. Out of 304 mothers who attended ANC 282(92.76) of mothers were getting information regarding the possible pregnancy and delivery related complications during their ANC follow up like, severe vaginal bleeding, severe headache, epigastric pain, blurring of vision, passage of liquor, prolonged labor, cord prolapse, fast and marked weight gain, fetal movement cessation, uterine rupture, and so on. The rest $22(7.24 \%)$ of mothers who 


\section{Journal of Complementary Medicine \& Alternative Healthcare}

attended ANC were not getting such kind of awareness regarding the possible pregnancy and delivery related complications. Two hundred twenty-one (cumulative frequency) (95.7\%) preference of those who attend ANC at health facility was due to their closeness to their residence and competent workers. About ten percent, $40(10.67 \%)$ of respondents were encountered abortion one to two times. Of the total reported pregnancies, $15.2 \%$ were unplanned. In this study, the prevalence of institutional and home delivery was $74.4 \%$ and $25.6 \%$ respectively. When mothers asked for their reasons why give birth at health institution they told that because they want to get better service, better outcome for their self and their new born, closeness to their living house and they also told that they were informed to have birth at the health institution. $4.3 \%$ of mothers gave birth at health institution because of they had a bad experience from past home delivery. And the reasons not to give birth at the health institution were $31.3 \%$ close attention from their family and relatives, $16 \%$ previous bad experience from health facility, $16.5 \%$ feeling more comfort while at home and the like. Regarding to husbands and other family members preference towards the place of delivery 275 (73.33\%) of husbands and $237(63.2 \%)$ of other family members prefer to give birth to the health facility (Table 2). This study revealed that the prevalence of institutional delivery service utilization was 74.4\% (Figure 1).

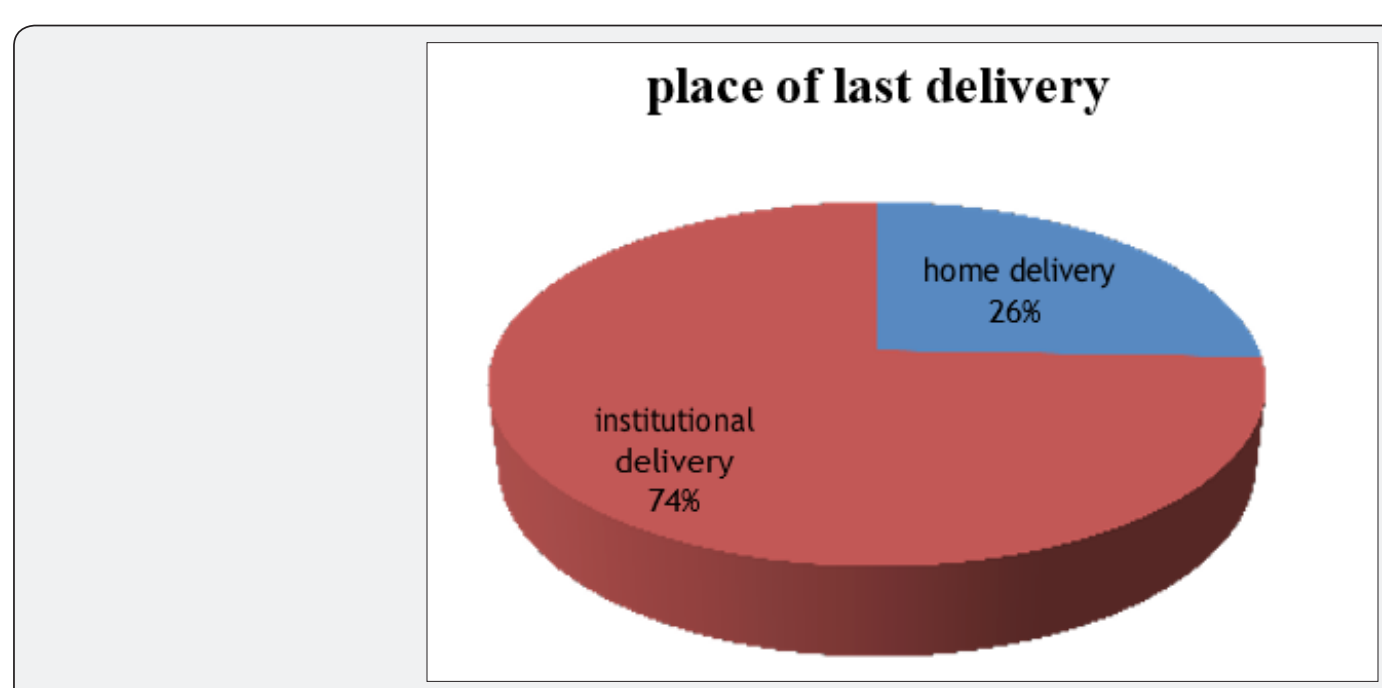

Figure 1: place of last delivery status among mothers who gave birth in the last 12 months prior to the study, in Jimma town, South West Ethiopia, 2016.

Table 2: Maternal and obstetric related variables among mothers who gave birth in the last 1 year in Jimma town, Oromia Region, Ethiopia, in 2016.

\begin{tabular}{|c|c|c|}
\hline Variables & Frequency & $\%$ \\
\hline \multicolumn{3}{|c|}{ Age at first marriage } \\
\hline$<15$ & 54 & 14.4 \\
\hline $15-19$ & 119 & 31.73 \\
\hline $20-24$ & 140 & 37.33 \\
\hline $25+$ & 62 & 16.54 \\
\hline \multicolumn{3}{|c|}{ Age at first pregnancy } \\
\hline$<15$ & 7 & 1.87 \\
\hline $15-19$ & 99 & 26.4 \\
\hline $20-24$ & 167 & 44.53 \\
\hline $25+$ & 102 & 27.2 \\
\hline \multicolumn{3}{|l|}{ Parity } \\
\hline$\leq 3$ & 227 & 60.53 \\
\hline$>3$ & 148 & 39.47 \\
\hline \multicolumn{3}{|l|}{ Gravidity } \\
\hline$\leq 3$ & 215 & 57.33 \\
\hline$>3$ & 160 & 42.67 \\
\hline \multicolumn{3}{|c|}{ Last delivery } \\
\hline Home & 96 & 25.6 \\
\hline
\end{tabular}


Journal of Complementary Medicine \& Alternative Healthcare

\begin{tabular}{|c|c|c|}
\hline Health institution & 279 & 74.4 \\
\hline \multicolumn{3}{|l|}{ Reasons to give birth at Health institution } \\
\hline To get better services in the health facility & 274 & 98.2 \\
\hline To get better outcome from health facility to me and my baby & 279 & 100 \\
\hline Bad experience from previous home delivery & 12 & 4.3 \\
\hline I was informed to deliver in a health facility & 256 & 91.75 \\
\hline Health facility nearest to my house & 22 & 7.88 \\
\hline \multicolumn{3}{|l|}{ Attending ANC in their last pregnancy } \\
\hline Yes & 304 & 81.07 \\
\hline No & 71 & 18.93 \\
\hline \multicolumn{3}{|l|}{ Place of ANC follow-up } \\
\hline Hospital & 165 & 54.28 \\
\hline Health center & 112 & 36.8 \\
\hline Private clinic & 27 & 8.92 \\
\hline \multicolumn{3}{|l|}{ Reasons of preference of that $\mathrm{HF}$} \\
\hline Close to their residence & 125 & 41.1 \\
\hline Competent health worker & 166 & 54.6 \\
\hline Other & 13 & 4.3 \\
\hline \multicolumn{3}{|l|}{ No of ANC visit } \\
\hline 1 & 38 & 12.5 \\
\hline 2 & 76 & 25 \\
\hline 3 & 101 & 33.27 \\
\hline$\geq 4$ & 89 & 29.7 \\
\hline \multicolumn{3}{|l|}{ Pregnancy lost (abortion) } \\
\hline Yes & 40 & 10.67 \\
\hline No & 335 & 89.33 \\
\hline \multicolumn{3}{|l|}{ Health facility visit } \\
\hline Yes & 345 & 82 \\
\hline No & 30 & 8 \\
\hline \multicolumn{3}{|l|}{ Reason for HF visit } \\
\hline For ANC & 304 & 88.2 \\
\hline For delivery & 12 & 3.48 \\
\hline For problems related to pregnancy & 16 & 4.64 \\
\hline For problems not related to pregnancy & 13 & 3.76 \\
\hline \multicolumn{3}{|c|}{ Mothers who got information regarding pregnancy and delivery related complications during your ANC follow up } \\
\hline Yes & 282 & 92.76 \\
\hline No & 22 & 7.24 \\
\hline \multicolumn{3}{|l|}{ What is the information's getting from the HF during your ANC visit } \\
\hline Sever vaginal bleeding, passage of liquor & 282 & 100 \\
\hline Severe headache, blurring of vision, epigastric pain fast and marked weight gain & 264 & 93.6 \\
\hline Prolonged labor, cord prolapsed & 275 & 97.5 \\
\hline Retained placenta, malpresentation & 268 & 95 \\
\hline
\end{tabular}




\section{Journal of Complementary Medicine \& Alternative Healthcare}

\begin{tabular}{|c|c|c|}
\hline Fetal movement cessation, uterine rupture, & 258 & 91.5 \\
\hline \multicolumn{3}{|l|}{ The last delivery (types) } \\
\hline Planned & 318 & 84.8 \\
\hline Unplanned & 57 & 15.2 \\
\hline \multicolumn{3}{|c|}{ Questions related to knowledge on pregnancy and delivery } \\
\hline \multicolumn{3}{|l|}{ What are the services given to pregnant mothers? } \\
\hline ANC service & 342 & 91.2 \\
\hline Delivery service & 366 & 97.6 \\
\hline Post-natal care & 358 & 95.5 \\
\hline Prevention of delivery complication & 362 & 96.5 \\
\hline Managing delivery complication & 279 & 74.4 \\
\hline Managing health problem of the new born & 321 & 85.6 \\
\hline \multicolumn{3}{|c|}{ What do you think the advantage of pregnancy and delivery related services? } \\
\hline For anticipating problems & 328 & 87.5 \\
\hline For early detection of health problem & 351 & 93.6 \\
\hline For the management of health problems & 375 & 100 \\
\hline For better health care to the mother and the new born & 375 & 100 \\
\hline \multicolumn{3}{|l|}{ Outcome of your last birth } \\
\hline Alive & 363 & 96.8 \\
\hline Still birth & 12 & 3.2 \\
\hline \multicolumn{3}{|l|}{ Preference of husbands towards the place of delivery } \\
\hline Home & 67 & 17.87 \\
\hline Health facility & 275 & 73.33 \\
\hline Don't know & 33 & 8.8 \\
\hline \multicolumn{3}{|l|}{ Preference of other family members towards the place of delivery } \\
\hline Home & 112 & 29.87 \\
\hline Health institution & 237 & 63.2 \\
\hline Don't know & 26 & 6.93 \\
\hline \multicolumn{3}{|l|}{ Final decision maker } \\
\hline Just me & 244 & 65.07 \\
\hline Husband & 72 & 19.2 \\
\hline My relatives/ partner & 35 & 9.34 \\
\hline \multicolumn{3}{|l|}{ Reasons for not giving birth at the health institutions } \\
\hline I feel more comfort at home & 16 & 16.66 \\
\hline Close attention from my family and relatives & 31 & 32.3 \\
\hline Previous bad experience from health institution & 16 & 16.66 \\
\hline Unwelcoming approach of health workers & 9 & 9.37 \\
\hline Dislike the service & 10 & 10.42 \\
\hline Labor was urgent to reach to health facility & 10 & 10.42 \\
\hline It was my usual practice & 4 & 4.17 \\
\hline
\end{tabular}

Out of 375 mothers who gave birth in the last 12 months prior to the study 318 (85\%) of them responded that their pregnancy was planned while the rest 57 (15\%) of the mother's pregnancy was unplanned from which majority was ending up with medical abortion (Figure 2). 
Journal of Complementary Medicine \& Alternative Healthcare

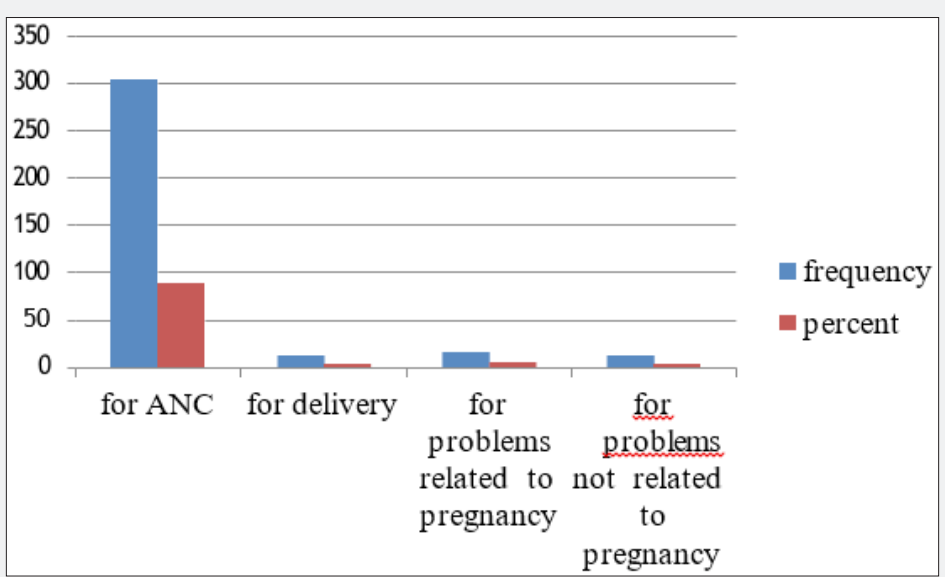

Figure 2: Reasons for visiting health facilities during the last pregnancy among mothers who gave birth in the last 12 months prior to the study, in Jimma town, South West Ethiopia, Aug. 2016.

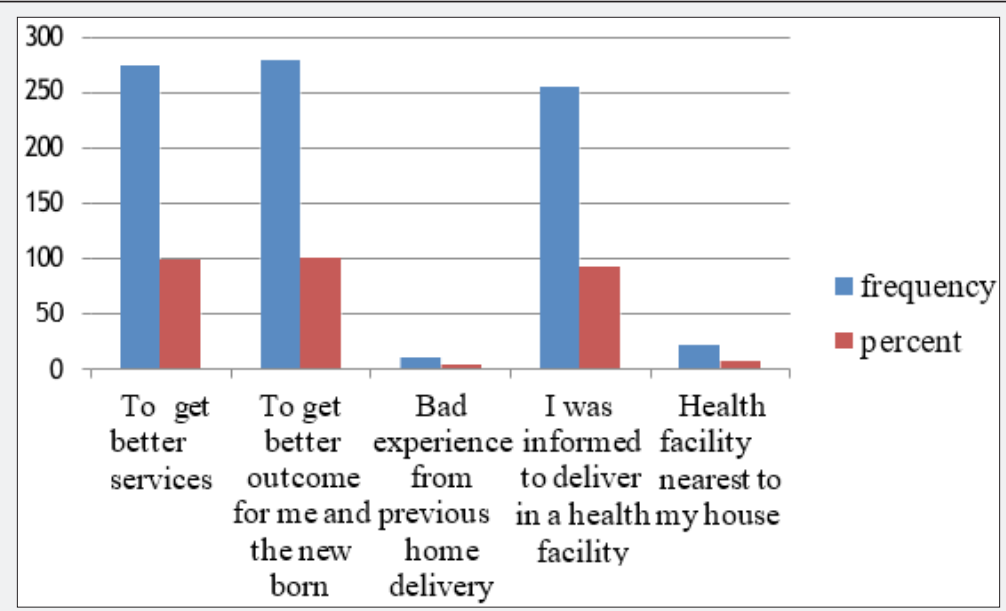

Figure 3: Reasons of mothers to gave birth at health facility among mothers who gave birth in the last 12 months prior to the study, in Jimma town, South West Ethiopia, Aug. 2016.

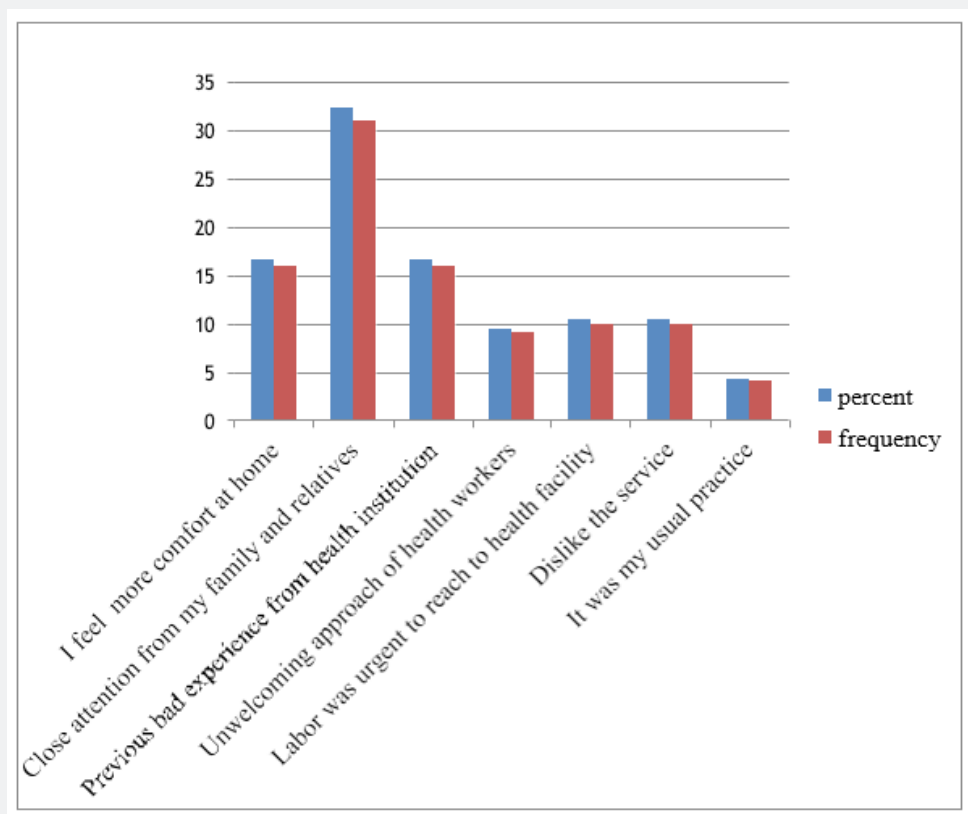

Figure 4: Reasons for home delivery during the last pregnancy among mothers who gave birth in the last 12 months prior to the study, Jimma town, South West Ethiopia, Aug. 2016. 


\section{Journal of Complementary Medicine \& Alternative Healthcare}

Among those mothers who visited health facilities, the reasons for visiting health facilities during the last pregnancy included ANC services (88.2), delivery, problems related to pregnancy and problems not related to pregnancy (Figure $3 \& 4$ ).

Many different reasons were forwarded for home delivery. Thirty one $(32.2 \%)$ of the mothers said having closer attention from family members, 16 (16.66\%) said just it was comfortable delivering at home is $4(4.37 \%)$ said it was my usual experience, $10(10.42 \%)$ said lab4r was short/urgent, 9(9.37\%) said unwelcoming approach of the health professional, 16 (16.66) they said previous bad experience from the health institution (Figure 5).

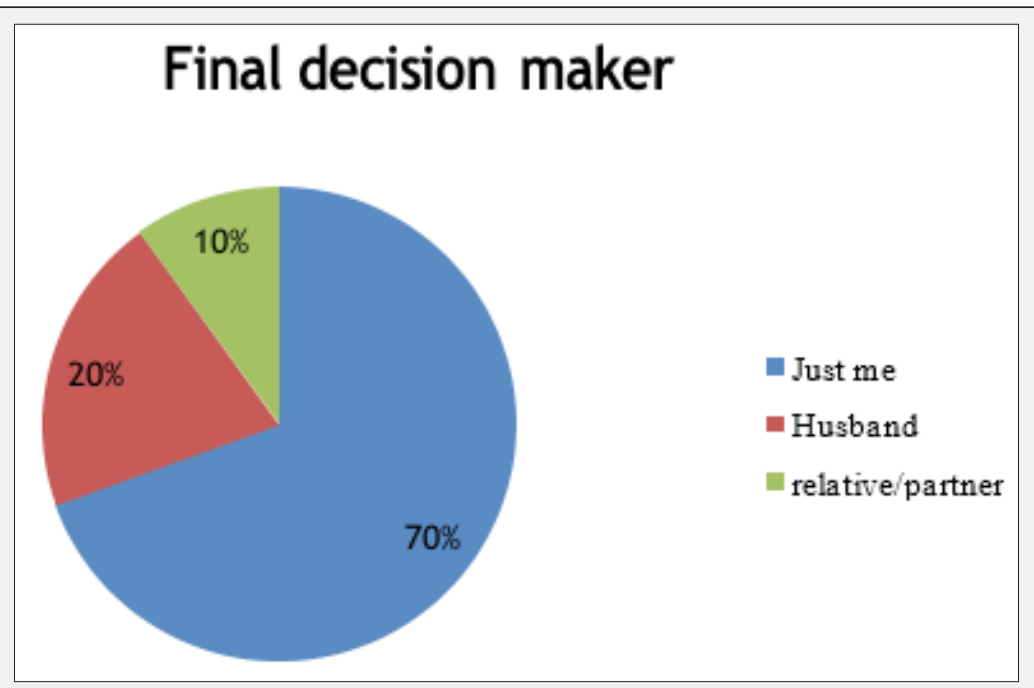

Figure 5: Final decision maker regarding place of delivery among mothers who gave birth in the last 12 months prior to the study, Jimma town, South West Ethiopia, Aug. 2016.

Majority $(70 \%)$ of mothers are the final decision makers regarding place of delivery followed by their husband $(20 \%)$ and their relatives/partners (10\%).

\section{Socio-demographic factors associated with institutional delivery service utilization}

In this study, among the socio-demographic variables, age of the mother at interview, occupational status of the mother and their husband and educational status of mothers and their husband were statistically associated with institutional delivery service use. In contrast, marital status, religion and ethnicity had no association with institutional delivery service utilization (Table 3).

Table 3: Socio-Demographic factors associated with institutional delivery service utilization among mothers who gave birth in the last 12 month, in Jimma town; Southwest Ethiopia, 2016.

\begin{tabular}{|c|c|c|c|}
\hline \multirow{2}{*}{$\begin{array}{c}\text { Variables } \\
\text { Age of the mother }\end{array}$} & \multicolumn{2}{|c|}{ Delivery at health institution } & \multirow{2}{*}{ Total } \\
\hline & Yes & No & \\
\hline $15-19$ & $15(16.37)$ & $7(5.63)$ & 22 \\
\hline $20-24$ & $74(70.68)$ & $21(24.32)$ & 95 \\
\hline $25-29$ & 99 (93.74) & $27(32.26)$ & 126 \\
\hline $30-34$ & $38(43.15)$ & $20(14.85)$ & 58 \\
\hline $35-39$ & $30(30.50)$ & $11(10.50)$ & 41 \\
\hline $40+$ & $23(24.55)$ & $10(8.45)$ & 33 \\
\hline Total & 279 & 96 & 375 \\
\hline statistics and decision & $\chi^{2 \mathrm{cal}}=5.025$ & $\chi^{2 \text { tab }} 0.4128, P=0.001$ & Associated \\
\hline \multicolumn{4}{|l|}{ Marital status } \\
\hline Single & $6(7.44)[0.28]$ & $4(2.56)[0.81]$ & 10 \\
\hline Married & $261(255.19)[0.13]$ & $82(87.81)[0.38]$ & 343 \\
\hline Divorced & $9(11.90)[0.71]$ & $7(4.10)[2.06]$ & 16 \\
\hline Widowed & $3(4.46)[0.48]$ & $3(1.54)[1.40]$ & 6 \\
\hline Total & 279 & 96 & 375 \\
\hline
\end{tabular}


Journal of Complementary Medicine \& Alternative Healthcare

\begin{tabular}{|c|c|c|c|}
\hline Statically decision & $\chi^{2}=6.2479$ & $P=0.101$ & Not associated \\
\hline Occupation of the mother & $\chi^{2}=41.6777$ & $\mathrm{p}-=<0.001$ & \\
\hline Private & $120(104.16)$ & $20(35.84)$ & 140 \\
\hline Governmental Employee & $73(64.73)$ & $14(22.27)$ & 87 \\
\hline Merchant & $61(69.19)$ & $32(23.81)$ & 93 \\
\hline Daily laborer & $12(18.60)$ & $13(6.40)$ & 25 \\
\hline Other & $13(22.32)$ & $17(7.68)$ & 30 \\
\hline Total & 279 & 96 & 375 \\
\hline Statically decision & $\chi^{2}=41.6777$ & $\mathrm{p}-=<0.001$ & Associated \\
\hline \multicolumn{4}{|l|}{ Occupation of the husband } \\
\hline Private & $92(72.39)$ & $4(23.61)$ & 96 \\
\hline Governmental Employee & $117(93.50)$ & $7(30.51)$ & 124 \\
\hline Merchant & $37(47.51)$ & $26(15.49)$ & 63 \\
\hline Daily laborer & $6(13.57)$ & $12(4.43)$ & 18 \\
\hline Others & 27 (52.03) & 47 (16.97) & 44 \\
\hline Total & 279 & 96 & 375 \\
\hline Statically decision & $\chi^{2}=121.1935$ & $\mathrm{P}<0.001$ & Associated \\
\hline \multicolumn{4}{|l|}{ Educational status of the mother } \\
\hline Illiterate & $19(35.71)$ & $29(12.29)$ & 48 \\
\hline Read and write & $30(45.38)$ & $31(15.62)$ & 61 \\
\hline Primary education & $120(104.90)$ & $21(36.10)$ & 141 \\
\hline Secondary and above & $110(93.00)$ & $15(32.00)$ & 125 \\
\hline Total & 279 & 96 & 375 \\
\hline Statically decision & $\chi^{2}=71.5442$ & $\mathrm{P}<0.001$ & Associated \\
\hline \multicolumn{4}{|l|}{ Educational status of the husband } \\
\hline Illiterate & $32(58.96)$ & $48(21.04)$ & 80 \\
\hline Read and write & $30(42.01)$ & 27 (14.99) & 57 \\
\hline Primary education & $58(49.38)$ & $9(17.62)$ & 67 \\
\hline Secondary and above & $149(118.65)$ & $12(42.35)$ & 161 \\
\hline Total & 269 & 96 & 365 \\
\hline Statically decision & $\chi^{2}=95.1494$ & $\mathrm{P}<0.001$ & Associated \\
\hline \multicolumn{4}{|l|}{ Religion } \\
\hline Muslim & $84(81.10)[0.10]$ & $25(27.90)[0.30]$ & 109 \\
\hline Orthodox & $100(95.23)[0.24]$ & $28(32.77)[0.69]$ & 128 \\
\hline Protestant & $70(72.91)[0.12]$ & $28(25.09)[0.34]$ & 98 \\
\hline Catholic & 13 (16.37) [0.69] & $9(5.63)[2.01]$ & 22 \\
\hline Other & $12(13.39)[0.14]$ & $6(4.61)[0.42]$ & 18 \\
\hline Total & 279 & 96 & 375 \\
\hline Statically decision & $\chi^{2}=5.0653$ & $\mathrm{P}=0.281$ & Not associated \\
\hline \multicolumn{4}{|l|}{ Ethnicity } \\
\hline Oromo & $123(125.74)[0.06]$ & $46(43.26)[0.17]$ & 169 \\
\hline Guragie & $49(52.82)$ [0.28] & $22(18.18)[0.80]$ & 71 \\
\hline Amhara & $96(87.05)$ [0.92] & $21(29.95)$ [2.68] & 117 \\
\hline Other & 11 (13.39) [0.43] & 7 (4.61) [1.24] & 18 \\
\hline Total & 279 & 96 & 375 \\
\hline Statically decision & $\chi^{2}=6.579$ & $\mathrm{P}=.086598$ & Not associated \\
\hline
\end{tabular}




\section{Journal of Complementary Medicine \& Alternative Healthcare}

Maternal and obstetric factors associated with institutional delivery service utilization

In this study obstetric and maternal variable; age at first marriage, number of pregnancies, type of pregnancy (planned Vs unplanned), attending ANC visit in their last pregnancy, number of ANC visit and number of live births showed statistically significant association with institutional delivery service use, while pregnancy loss (abortion) has no association with that of institutional delivery service utilizations (Table 4).

Table 4: Maternal and obstetric factors associated with institutional delivery service utilization among mothers who gave birth in the past 12 months, in Jimma Town; Oromo region, Southwest Ethiopia, 2016.

\begin{tabular}{|c|c|c|c|}
\hline Variables & Delivery at health institution & & \\
\hline Age at first marriage & Yes & No & Total \\
\hline$<15$ & $25(40.18)$ & $29(13.82)$ & \\
\hline $15-19$ & $92(88.54)$ & $27(30.46)$ & \\
\hline $20-24$ & $110(104.16)$ & $30(35.84)$ & \\
\hline $25+$ & $52(46.13)$ & 10 (15.87) & \\
\hline Total & 279 & 96 & \\
\hline statistics and decision & $\chi^{2}=27.1211$ & $\mathrm{p}-=<0.001$ & Associated \\
\hline \multicolumn{4}{|l|}{ Age at First Pregnancy } \\
\hline$<15$ & $3(5.21)$ & $4(1.79)$ & \\
\hline $15-19$ & $52(73.66)$ & $47(25.34)$ & \\
\hline $20-24$ & $134(124.25)$ & $33(42.75)$ & \\
\hline $25+$ & $90(75.89)$ & $12(26.11)$ & \\
\hline Total & 279 & 96 & \\
\hline statistics and decision & $\chi^{2}=41.7694$ & $\mathrm{p}-=<0.001$ & Associated \\
\hline \multicolumn{4}{|l|}{ Number of Live Births (Parity) } \\
\hline$<3$ & 194 (168.89) [3.73] & 33 (58.11) [10.85] & 227 \\
\hline$\geq 3$ & $85(110.11)$ [5.73] & 63 (37.89) [16.64] & 148 \\
\hline Total & 279 & 96 & 375 \\
\hline statistics and decision & $\chi^{2}=36.9567$ & $\mathrm{p}-=<0.001$ & Associated \\
\hline \multicolumn{4}{|c|}{ Number Of Pregnancy (Gravidity) } \\
\hline$<3$ & 173 (159.96) [1.06] & $42(55.04)[3.09]$ & 215 \\
\hline$\geq 3$ & $106(119.04)$ [1.43] & $54(40.96)[4.15]$ & 160 \\
\hline Total & 279 & 96 & 375 \\
\hline statistics and decision & $\chi^{2}=9.7323$ & $\mathrm{P}=.002$ & Associated \\
\hline \multicolumn{4}{|l|}{ Last Pregnancy } \\
\hline Planned & 251 (236.59) [0.88] & $67(81.41)[2.55]$ & 318 \\
\hline Unplanned & $28(42.41)[4.90]$ & 29 (14.59) [14.23] & 57 \\
\hline Total & 279 & 96 & 375 \\
\hline statistics and decision & $\chi^{2}=22.5488$ & $\mathrm{p}=<0.001$ & Associated \\
\hline \multicolumn{4}{|c|}{ Attending ANC in their last pregnancy } \\
\hline Yes & $233(226.18)[0.21]$ & $71(77.82)[0.60]$ & 304 \\
\hline No & $46(52.82)[0.88]$ & 25 (18.18) [2.56] & 71 \\
\hline Total & 279 & 96 & 375 \\
\hline Statistically decision & $\chi^{2}=4.2478$ & $\mathrm{p}=0.039$ & Associated \\
\hline \multicolumn{4}{|l|}{ Statistically decision } \\
\hline \multicolumn{4}{|l|}{ Pregnancy lost (abortion) } \\
\hline Yes & $26(29.76)[0.48]$ & $14(10.24)$ [1.38] & 40 \\
\hline
\end{tabular}


Journal of Complementary Medicine \& Alternative Healthcare

\begin{tabular}{|c|c|c|c|}
\hline No & $253(249.24)[0.06]$ & $82(85.76)[0.16]$ & 335 \\
\hline Total & 279 & 96 & 375 \\
\hline Statistically decision & $\chi^{2}=2.0773$ & $\mathrm{P}=0.149$ & Not associated \\
\hline
\end{tabular}

\section{Discussion}

This community - based study attempted to identify the magnitude of institutional delivery service utilization and associated factors among mothers who gave birth in the last 12 months prior to the study in Jimma Town. Despite the relative accessibility of health institutions in urban areas, a significant number of urban resident women still delivered at home. The study results showed that home delivery in the Town was $25.6 \%$ and the majority of mothers $(74.4 \%)$ gave birth at the health institution which made the result unsatisfactory. It means overall delivery assisted by skilled birth attendants was $74.4 \%$. This study finding was higher than National and Oromia region mini EDHS result of 2014 [3] which was $16 \%$ and $13.1 \%$ respectively but it is lower than Addis Ababa (86.1\%); the reason for these big difference might be due the fact that in urban areas the proportion of mothers with education is higher, accessibility of the services with minimal distance and transport, and mothers could have better decision making autonomy, good knowledge of pregnancy and delivery complications, and better access to information than rural mothers [4].

The finding was much lower when we compare with the findings of community based cross sectional study on mothers who gave birth 12 months prior to the study done in Bihar Dar city administration (urban mother accounts only 83.4\%) in 2014, was $78.8 \%$ but it was in consistent with cross sectional follow up study done at Debra Marcos town in 2015, which was74.3\% [5,6]. But from the mini EDHS result of 2014 [3] the finding was much better than others like Amhara region, Tigray region and Dire Dawa town in which delivery service utilization rate was $11.7 \%, 26.2 \%$ and $59.2 \%$ respectively. This large difference could be due study done in Amhara Region and Tigray region included both urban and rural in which the negative influence of husbands and family members could be lower than Rural Keble, and Urban mothers might be able to decide on their own health [4-9].

Proportion of women attending antenatal clinic and delivery in health facility: Antenatal care (ANC) services provide opportunities for health workers to promote a specific place of deliver or give women information on the status of their pregnancy, which in turn informs their decisions on where to deliver. Risk assessment during ANC may explicitly recommend a place of delivery, for instance to deliver in a hospital for a twin pregnancy under normal circumstances [10-12].

WHO recommends that pregnant mother without any complications have at least four antenatal care clinics to provide sufficient information for the mother and the developing embryo In this study, 304(81\%) had attended antenatal clinic (ANC). this is slightly higher than that of national estimate of $54 \%$ (EDHS -2014) $(3,18)$ and slightly lower than findings of studies conducted in Debra Marcos town (88.5\%). This study also found that Concerning to number of ANC visit, Out of 304 women attended antenatal clinic, most of them 190 (62.5\%) attended more than three visits and 114 (37.5\%) attended three and above visits. In this study, age at first marriage and early ANC visits were also factors associated with institutional delivery service use. Similarly, planned pregnancy, parity of below three children and gravidity of less than three were important factor associated with institutional delivery service use in this study [13].

There is also an association between mother's education and place of delivery. The proportion of births delivered in a health facility is only $39 \%$ percent among uneducated mothers, and $50 \%$ percent among mothers who able to read and write compared with $86 \%$ percent among mothers with primary and higher education [14].

The prevalence of unplanned pregnancy from the study subjects were $15 \%$ which is slightly lower than a study conducted at Bahir Dar city administration in 2014 which was 19\%. The gap might be due to there is a two year different between the two research studied and women became aware and have a good attitude towards the modern contraceptive method and most of the mothers might use the service [15].

From the total 375 about $40(10.67 \%)$ of respondents were encountered abortion one to two times. And majority of them are from unplanned pregnancy because most of mothers who face such kind of challenge they want to abort and the pregnancy ends up with abortion [16].

From the different reasons forwarded from respondent mothers for the preference home delivery majority thirty one $(32.2 \%)$ of the mothers said having closer attention from family members, $16(16.66 \%)$ said just it was comfortable delivering at home is $4(4.37 \%)$ said it was my usual experience, $10(10.42 \%)$ said lab4r was short/urgent, 9(9.37\%) said unwelcoming approach of the health professional, 16 (16.66) they said previous bad experience from the health institution $[17,18]$.

This study also shows that most mothers preferred to give birth to the health institution because of they want to get a better service from the health institution, to get better outcome for their self and to the newborn, some of them were informed when and where to give birth [19].

\section{Conclusion}

In this study, institutional delivery service utilization is optimal. Institutional delivery service use among women in Jimma Town was higher compared with the national and regional estimates, higher proportion of women from the selected Keble's of the Town gave birth at home. Closer attention and care from family members and relatives, delivering at home is usual experience, having much freedom at home during delivery, influence from 
the husband and other family members, disliking the services provided at the health facilities, bad experience from previous health facility delivery, labor was unexpected/short and absence of problem were the main reasons given by mothers not attending health care delivery. Factors such as age at first marriage, age at first pregnancy, types of pregnancy (planned/unplanned),parity, gravidity, occupation, ANC visit during the last pregnancy, frequency of ANC visit, educational status of the mother and their husband and knowledge of the mothers on pregnancy and delivery services were significantly associated with skilled delivery service utilization.

\section{Declarations}

\section{Acknowledgment}

We would like to express our deepest gratitude and appreciation to JUIH, and health professionals working at each health facilities. We also aknowledge Jimma University -Institute of health-IRB for securing ethical letter and for the fund provided.

\section{Ethics approval and consent to participate}

Ethical clearance and an approval letter obtained from Jimma University institute of health- institutional reviewing board, then support letter obtained from JU to the study area. Confidentiality was maintained by using anonymous codes or number.

\section{Consent to publish}

All parties involved agreed to publish on international peer reviewed journal. During data collection, all concerned body informed and agreed on the major objective of the study which is for accademic purpose including publication.

\section{Availability of data and materials}

The datasets or hard copies used and/or analyzed during the current study are available. All data generated or analyzed during this study are included in this manuscript.

\section{Competing/Conflict of interest}

All authors declare that they have no any financial and nonfinancial competing interests. None of the authors of this paper has a financial or personal relationship with other people or organizations that could inappropriately influence or bias the content of the paper.

\section{Authors' contributions}

Yibeltal Siraneh B had made substantial contributions to conception, design, analysis and interpretation of data including manuscript preparation. Fisseha $\mathrm{W}$ worked a lot in acquisition of data and reviewed the manuscript for the intellectual content. All authors read and approved the final manuscript.

\section{References}

1. WHO (2010) Trends in Maternal Mortality 1990 to 2008. Estimates developed by WHO, UNICEF, UNFPA and the World Bank. Geneva, Switzerland.
2. United Nations (2008) Millennium Development Goals Report, New York, USA.

3. Central Statistical Agency [Ethiopia] and ORC Macro (2006) Ethiopia Demographic and Health Survey 2005. Addis Ababa, Ethiopia and Calverton, Maryland, USA: Central Statistical Agency and ORC Macro's, pp. 232-233.

4. Central Statistical Agency Ethiopia (2014) Ethiopia Mini Demographic and Health Survey 2014. Addis Ababa, Ethiopia.

5. Gedefaw A, Muluken A, Tesfaye S (2014) Assessment of utilization of Institutional delivery services and associated factors among mothers who gave birth 12 months prior to the study in Bahir Dar city administration. Ethiopian Journal of Reproductive Health 22.

6. Hinsermu B, Mulatu A, Abdella A and Mulunesh A (2015) Pregnant women's preference and factors associated with institutional delivery service utilization in Debra Markos Town, North West Ethiopia, BMC Pregnancy and Childbirth 15: 15.

7. Hogan MC, Foreman KJ, Naghavi M (2010) Maternal Mortality for 181 countries, 1980-2008: A systematic analysis of progress towards MDG5.

8. FMOH, UNICEF, UNFPA, WHO and AMDD (2008) National Baseline Assessment for Emergency Obstetric \& Newborn Care in Ethiopia, pp. 18

9. WHO (2007) Maternal Mortality in 2005. Estimates Developed by WHO, UNICEF and UNFPA. Geneva, Switzerland.

10. World Health Organization (1997) Safe motherhood technical consultation, Colombo. World Health Organization, Geneva, Switzerland.

11. Koblinsikyet Al (1999) Organizing delivery care. What works for safe motherhood? Bull World Health Organ 77(5): 399-406.

12. Rose NM Mpembeni, Japhet Z Killewo, et al. (1995) Use pattern of maternal health services and determinants of skilled care during delivery in Southern Tanzania: implications for achievement of MDG5 targets. Journal of Health development 8(2): 22-27.

13. Fantahun M (1992) Factors affecting ANC attendance and preference of delivery by pregnant women in Guleleworeda, Ethiopian Journal of Health development 6(2): 17-22.

14. Millennium Development Goals- Online Available-Document (2008).

15. Report on safe motherhood conference 1987 preventing the tragedy of maternal death; A report on the international safe motherhood conference, Nairobi, Kenya.

16. Royston E (1989) The status of women and maternal mortality. In preventing maternal deaths, WHO.

17. Pricey Yesudian P (2004) Impact of women's empowerment Autonomy and attitude on maternal health care utilization in India. Global forum for Health research: forum 8, Mexico City.

18. Ahmed S, Parveen A. Khanum Ariful Islam Sadia D. Parveen Farzana Sobhan, et al. (1997) strengthening maternal and neonatal health results from two rural villages of Bangladesh. Dhaka. International Center for Diarrheal Disease Research. MCH-FP Extension project working paper, 137; ICDDR, working paper 86.

19. Mesfin Nigussie (2004) Assessment of safe delivery service utilization among women of childbearing age in north Gondar Zone. Ethiopian Journal of Health development 18(3). 
This work is licensed under Creative Commons Attribution 4.0 License

DOI: 10.19080/JCMAH.2018.08.555736
Your next submission with Juniper Publishers will reach you the below assets

- Quality Editorial service

- Swift Peer Review

- Reprints availability

- E-prints Service

- Manuscript Podcast for convenient understanding

- Global attainment for your research

- Manuscript accessibility in different formats

( Pdf, E-pub, Full Text, Audio)

- Unceasing customer service

Track the below URL for one-step submission https://juniperpublishers.com/online-submission.php 